\title{
SILÍCIO PROMOVE MELHOR CONSERVAÇÃO PÓS-COLHEITA DA ALFACE
}

\author{
Luanda Torquato Feba, Eduardo Henrique Lima Mazzuchelli, Patrícia Reines Carvalho, Viviane \\ Cacefo
}

Universidade do Oeste Paulista - UNOESTE, Agronomia, Presidente Prudente, SP. E-mail: lu feba@hotmail.com

\begin{abstract}
RESUMO
A alface (Lactuca sativa L.) é uma folhosa altamente consumida e apresenta vida pós-colheita curta, gerando assim muitas perdas e prejuízos. Na horticultura, o uso do silício tem demonstrado efeito benéfico da sua utilização em diversas plantas. Nesse sentido, o objetivo desse trabalho foi verificar a influência da aplicação foliar de doses crescentes de silicato de magnésio na produção e conservação pós-colheita da alface crespa. O silício por possuir relação direta na preservação contra danos oxidativos e na manutenção dos teores de clorofila, proporcionou um retardo à senescência e consequentemente uma melhor conservação pós-colheita da alface, prolongando por dois dias a sua vida útil na dose de $0,32 \mathrm{~g} / \mathrm{L}$. Porém, a aplicação de silicato de magnésio não promoveu o crescimento da alface crespa.
\end{abstract}

Palavras-chave: Lactuca sativa L.. Horticultura. Perecibilidade. Nutriente. Silicato de magnésio.

\section{SILICON PROMOTES BETTER POST-HARVEST CONSERVATION OF LETTUCE}

\begin{abstract}
Lettuce (Lactuca sativa L.) is a heavily consumed hardwood and presents a short post-harvest life, thus generating many losses. In horticulture, the use of silicon has shown beneficial effect of its use in several plants. In this sense, the objective of this study was to verify the influence of foliar application of increasing doses of magnesium silicate on the production and post-harvest conservation of crisp lettuce. Due to its direct relationship in the preservation of oxidative damage and the maintenance of chlorophyll content, silicon provided a delay in senescence and a better postharvest conservation of the lettuce, extending its shelf life by $0.32 \mathrm{~g} / \mathrm{L}$. However, the application of magnesium silicate did not promote the growth of crisp lettuce.
\end{abstract}

Key words: Lactuca sativa. Horticulture. Perishability. Nutrient. Magnesium silicate.

\section{INTRODUÇÃO}

A alface é a folhosa mais consumida no Brasil, e seu cultivo é amplo, abrangendo diversas regiões produtoras localizadas próximo aos centros de consumo, por ser um alimento altamente perecível. Assim, o cuidado com as hortaliças deve começar no campo e se estender até o momento do consumo. Pois essas estão sujeitas à condições adversas, como a temperatura, por exemplo, que afetam diretamente a respiração, transpiração e outros aspectos fisiológicos da planta, agravando a velocidade de deterioração desses produtos, reduzindo o tempo de "vida de prateleira". As perdas pós-colheita de todos os tipos de alimentos são geralmente maiores nos países em desenvolvimento ou emergentes, como o Brasil, onde os índices estimados podem atingir $30 \%$ ou mais da produção (CHITARRA; CHITARRA, 2005). 
Com o aumento da população mundial cresce a necessidade de aumentar a produção de alimentos, o que nos remete a pensar que há necessidade de aumentar a área cultivada, investimentos em insumos e defensivos. Uma opção mais viável consiste em reduzir as perdas que ocorrem desde a produção até a comercialização, chegando ao consumidor (COSTA; GUILHOTO; BURNQUIST, 2015). Estudos indicam que o uso do silício tem demonstrado efeito benéfico da sua utilização em diversas plantas da horticultura (MARODIN, 2011).

Embora o silício seja considerado o segundo elemento mais abundante na crosta terrestre, nos solos tropicais sua disponibilidade é limitada, pois está basicamente, na forma de opala e quartzo, que não são assimiláveis. Além disto, nos solos classificados como arenosos, sua disponibilidade para as plantas é ainda menor, por apresentar drenagem excessiva nos perfis do solo (BARBOSA FILHO et al., 2001).

Neste contexto, o objetivo deste trabalho foi verificar a influência da aplicação foliar de doses crescentes de silicato de magnésio na produção e conservação pós-colheita de alface crespa.

\section{MATERIAL E MÉTODOS}

O experimento foi conduzido na horta da Universidade do Oeste Paulista (UNOESTE), Presidente Prudente - SP (2217'27' S; 51눋ㄴ' O; 385 m de altitude), no período do outono de 2016, com temperaturas médias de 26,7으.

O delineamento experimental utilizado foi em blocos casualizados, com cinco tratamentos e dez repetições, sendo cada planta considerada como uma repetição. No início do experimento foram selecionadas 50 mudas de alface crespa (Lactuca sativa L.), var. Vanda, com cerca de $7 \mathrm{~cm}$ de altura, as quais foram previamente obtidas de sementes germinadas em bandeja de poliestireno expandido com 128 células e utilizado substrato comercial Carolina ${ }^{\circledR}$ (a base de vermiculita e casca de pinus). Posteriormente, aos quatorze dias após a semeadura foram transplantadas para sacos plásticos com capacidade de $5 \mathrm{~L}$, preenchido com $70 \%$ de argissolo vermelho distroférrico e $30 \%$ de húmus de minhoca. Durante a condução do experimento foi utilizada irrigação por aspersão em três períodos do dia, no início da manhã ( $8 \mathrm{~h}$ ), ao meio dia e ao final da tarde (16 h), onde a lâmina de irrigação correspondia a $100 \%$ da evapotranspiração da cultura (ETc).

Os tratamentos consistiram em aplicações de silicato de magnésio (SiMg) composto de $65 \%$ de $\mathrm{SiO}_{2}$ e 14\% de $\mathrm{MgO}$, nas seguintes concentrações: 0,0 (controle, sendo aplicado água e $14 \%$ de $\mathrm{MgO}) ; 0,16 ; 0,32 ; 0,48$ e 0,64 g/L pulverizadas manualmente com borrifador aplicando 50 $\mathrm{mL}$ da solução por planta, sendo realizada a cada sete dias via foliar, totalizando três aplicações. A primeira aplicação foi realizada aos doze dias após o transplante das bandejas para os sacos, e a última ocorreu 26 dias após o transplantio.

Aos 29 dias após o transplantio, as plantas foram retiradas dos sacos plásticos, retiradas as raízes e foram avaliados os seguintes parâmetros: peso (g/planta), diâmetro da cabeça da alface $(\mathrm{cm})$ e altura $(\mathrm{cm})$ das plantas da base até a folha mais alta. Em seguida, as plantas foram dispostas sobre bancada, dentro de saquinhos de formato cônico com múltiplos furos para ventilação onde foram feitas as avaliações pós-colheita.

As avaliações foram realizadas a cada dois dias até chegarem a uma condição em que estariam impróprias para comercialização, acompanhando-se o seguinte critério de notas: nota 0 cabeças com apenas duas folhas ou menos (sem condição de comercialização); nota 1 - cabeças 
com mais de 3 folhas deterioradas (ainda aptas à comercialização); nota 2 - cabeças com no máximo 3 folhas deterioradas (aptas à comercialização); nota 3 - cabeças aptas à comercialização sem deterioração (Figura 1).

Figura 1 - Critério de notas para avaliação de plantas para comercialização.
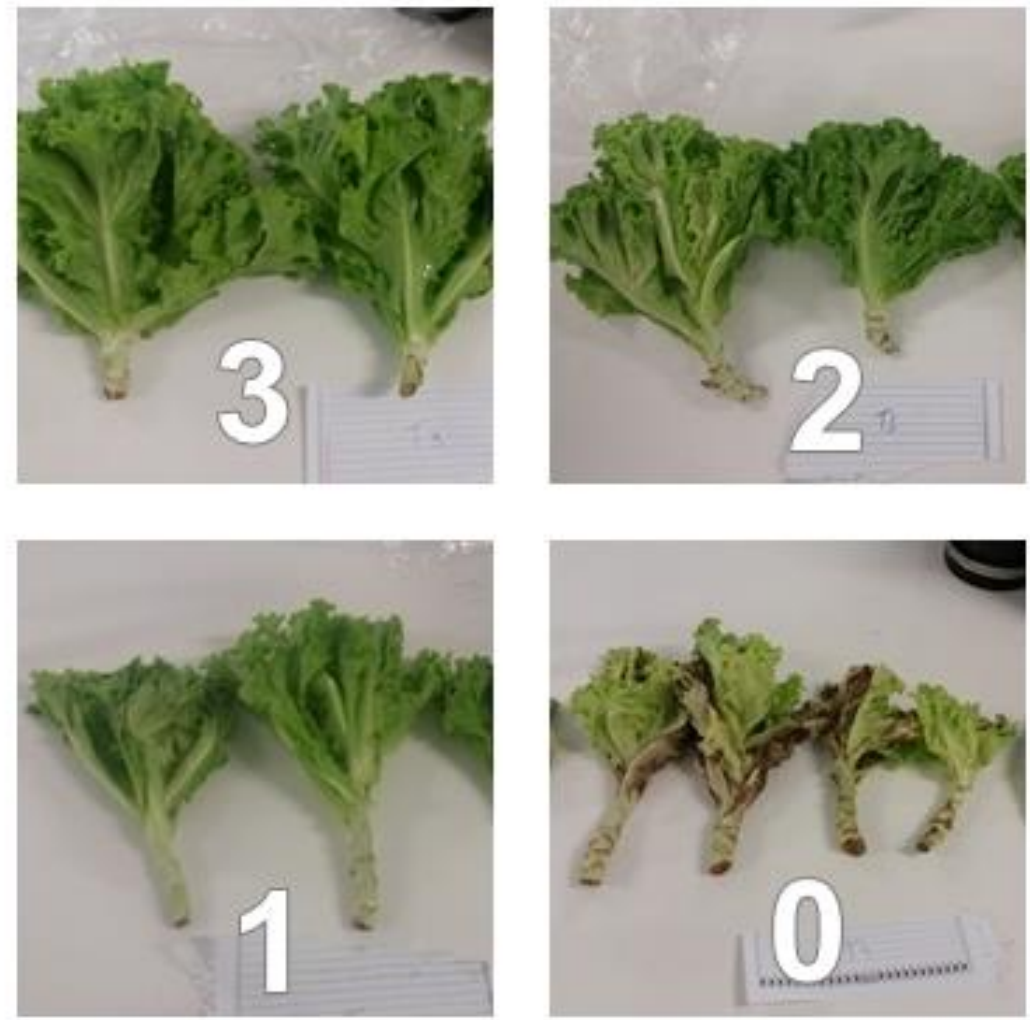

Os dados de peso, diâmetro e altura das plantas foram submetidos à análise de variância, sendo as médias comparadas pelo teste de Tukey ao nível de $5 \%$ de probabilidade. As notas médias obtidas na avaliação pós-colheita realizada no $11^{\circ}$ dia, onde ainda havia plantas aptas à comercialização, foram submetidas à análise de regressão nas diferentes concentrações de $\mathrm{SiMg}$ aplicado nas plantas de alface. Para as análises descritas foi utilizado o programa estatístico SISVAR versão 5.3 (FERREIRA, 2010).

\section{RESULTADOS}

Nas médias dos parâmetros de crescimento da alface crespa sob diferentes concentrações de silicato de magnésio (SiMg), observa-se que não houve diferença significativa para nenhum dos parâmetros com aplicação de silício (Tabela 1).

Tabela 1 - Peso, diâmetro e altura da alface crespa em função da aplicação foliar com diferentes concentrações de silicato de magnésio (SiMg).

\begin{tabular}{lccc} 
Concentração de $\operatorname{SiMg}(\mathrm{g} / \mathrm{L})$ & $\begin{array}{c}\text { Peso } \\
(\mathrm{g})\end{array}$ & $\begin{array}{c}\text { Diâmetro } \\
(\mathrm{cm})\end{array}$ & $\begin{array}{c}\text { Altura } \\
(\mathrm{cm})\end{array}$ \\
\hline
\end{tabular}




\begin{tabular}{cccc}
\hline 0,0 & 166,1 & 25,1 & 26,4 \\
0,16 & 168,2 & 26,2 & 24,7 \\
0,32 & 157,8 & 24,1 & 25,2 \\
0,48 & 168,3 & 26,6 & 26,5 \\
0,64 & 172,8 & 23,5 & 24,5 \\
\hline CV (\%) & 35 & 31 & 29
\end{tabular}

Médias seguidas pela mesma letra não apresentam diferença estatística entre as concentrações de silicato de magnésio para cada parâmetro avaliado (peso, diâmetro e altura). Valores apresentados como média $(n=10)$. Teste de Tukey $(p<0,05)$.

Com relação à avaliação pós-colheita, observou-se diferenças significativas para a avaliação aos onze dias após a colheita, onde evidenciou-se que a dose de 0,32 g/L de SiMg promoveu a melhor conservação pós-colheita da alface, aumentando a vida útil em mais dois dias, possibilitando apenas a comercialização das plantas oriundas desse tratamento (Tabela 2 e Figura 2).

Tabela 2 - Notas atribuídas às plantas de alface crespapós-colheita em função da aplicação foliar com diferentes concentrações de silicato de magnésio (SiMg).

\begin{tabular}{cccccccc}
\hline Concentração & \multicolumn{7}{c}{ Dias após a colheita da alface } \\
\cline { 2 - 8 } De SiMg (g/L) & 1 & 3 & 5 & 7 & 9 & 11 & 13 \\
\hline & 3 & 1,8 & 1,7 & 1,5 & 1,1 & 0,6 & 0 \\
0,0 & 3 & 1,9 & 2,1 & 2,0 & 1,2 & 0,8 & 0 \\
0,16 & 3 & 2,3 & 2,3 & 2,1 & 2,0 & 1,4 & 0,6 \\
0,32 & 3 & 2,1 & 2,1 & 2,0 & 2,0 & 0,9 & 0,2 \\
0,48 & 3 & 1,6 & 1,5 & 1,4 & 1,2 & 0,6 & 0 \\
0,64 & 3 & 1,98 & 1,94 & 1,8 & 1,5 & 0,9 & 0,16 \\
\hline Médias & & 78 Notas
\end{tabular}


Figura 2 - Análise de regressão de doses de silicato de magnésio (SiMg) em relação as médias de notas na conservação pós colheita da alface crespa.

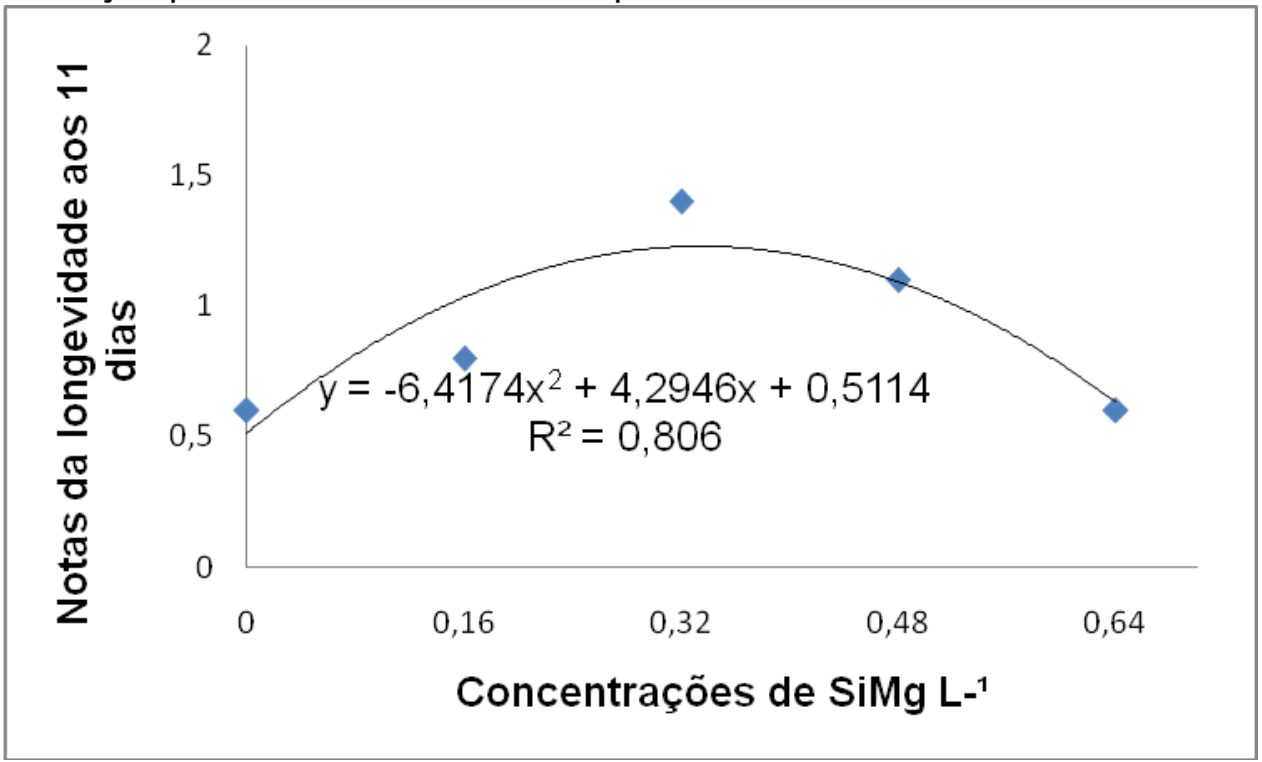

Durante o experimento, observou-se que a aplicação de silício promoveu menor oxidação das folhas, as quais conservaram melhor a cor verde, sendo que as plantas que não receberam a aplicação apresentaram coloração marrom, com maior grau de oxidação dos tecidos.

\section{DISCUSSÃO}

Estudos com a aplicação de silício na produção de hortaliças ainda são poucos, porém há relatos da não influência desse nutriente no crescimento e, consequentemente, na produtividade da alface como observado neste trabalho (Tabela 1).

Avaliando a produtividade e o estado nutricional de cultivares de alface Raider com aplicação de silício, Ferreira et al. (2009) não observaram aumento desses parâmetros nem no teor de silício na parte aérea das plantas. Em rúcula, também não houve efeito significativo para altura, área foliar, fitomassa fresca total, fitomassa seca total, razão de área foliar, peso específico da folha e quantidade de água na parte aérea em relação às cinco doses de silício aplicadas (GERRERO; BORGES; FERNANDES, 2011).

Apesar da não influência do silício no crescimento da alface, nossos dados mostram que este nutriente promoveu melhor conservação pós-colheita dessa hortaliça (Tabela 2 e Figura 2). Shi et al. (2013), sugerem que um dos papéis do silício nos tecidos vegetais está relacionado à funções fisiológicas, como o aumento do metabolismo antioxidante, outra função relacionada, seria a menor transpiração pelo acúmulo do elemento nas folhas.

O silício é transportado via xilema e é distribuído conforme a taxa de transpiração dos tecidos, idade da planta, tipo e localização dos tecidos envolvidos. Segundo Yoshida (1975), grande parte desse nutriente é depositado nas folhas ( $71 \%$ do total), caule $(13 \%)$, raízes (10\%) e colmo (6\%). Após ser absorvido, o ácido monossilícico é depositado na forma de sílica amorfa hidratada e sílica polimerizada, em tecidos jovens e células senescentes, respectivamente (MA; YAMAJI, 2008).

Avaliando alface americana minimamente processada, Galati et al. (2015) observaram que a concentração de $84 \mathrm{mg} / \mathrm{L}$ de silício propiciou maior firmeza das folhas, deixando-as mais túrgidas 
e conservando sua vida útil por 16 dias. Em plantas de Dendrobium nobile, o fornecimento de 0,45 $\mathrm{g} / \mathrm{L}$ de SiMg promoveu o aumento da longevidade de flores em quatro dias (CARVALHO et al., 2013).

O tratamento com silício reduz a transpiração, mantém a célula mais túrgida e, consequentemente, a firmeza das folhas, prolongando o período de armazenamento (KIM et al., 2002).

Os benefícios do silício conferidos às plantas tem sido associados a diversos ao aumento na eficiência da capacidade fotossintética, redução da transpiração, aumento da resistência mecânica das células, resistência a pragas e doenças, redução da acumulação tóxica de $\mathrm{Mn}$, Fe e Al e outros metais pesados, e aumento na absorção do P (KORNDÖRFER; DATNOFF, 1995). Além disso, esse nutriente contribui para a estruturação da parede celular de raízes e folhas. Isso aumenta os conteúdos de hemicelulose e lignina, aumentando a rigidez da célula. Assim, a ação do silício provoca efeitos indiretos nas plantas (RESENDE; YURI; SOUZA, 2007).

A menor oxidação nas folhas também foi observado por Resende, Yuri e Souza (2007) ao analisarem diferentes épocas de plantio e doses de silício no rendimento de alface tipo americana.

A melhor conservação pós-colheita da alface também pode ser explicada pelo efeito positivo do silício na manutenção dos teores de clorofila, o que retarda a senescência foliar e prolonga a vida útil do vegetal (GOTTARDI et al., 2012).

Há pouco tempo, a adubação com silício vem sendo indicada como uma alternativa para prolongar a conservação pós-colheita de frutas e hortaliças (GALATI et al., 2015).

\section{CONCLUSÃO}

O silício por possuir relação direta na preservação contra danos oxidativos e na manutenção dos teores de clorofila, proporcionou um retardo à senescência e consequentemente uma melhor conservação pós-colheita da alface, prolongando por dois dias a sua vida útil na dose de $0,32 \mathrm{~g} / \mathrm{L}$. Porém, a aplicação de silicato de magnésio (SiMg) não promoveu o crescimento da alface crespa.

\section{REFERÊNCIAS}

BARBOSA FILHO, M. P.; et al. Silicato de cálcio como fonte de silício para o arroz de sequeiro. Revista Brasileira de Ciência do Solo, Viçosa, v. 25, n. 2, p. 325-330, 2001.

CARVALHO, P. R. et al. Efeito do silício na qualidade de flores de Dendrobium nobile (Orchidaceae). Semina: Ciências Agrárias, Londrina, v. 34, n. 4, p. 1615-1622, jul./ago. 2013.

CHITARRA, M. I. F.; CHITARRA, A. B. Pós-colheita de frutas e hortaliças: fisiologia e manuseio. Lavras: FAEPE, 2ed. 783p. 2005.

COSTA, C. C. da; GUILHOTO, J. J. M.; BURNQUIST, H. L. Impactos socioeconômicos de reduções nas perdas pós-colheita de produtos agrícolas no Brasil. RESR, Piracicaba, v. 53, n. 3, p. 395-408, jul./set. 2015. https://doi.org/10.1590/1234-56781806-9479005303002

FERREIRA, D. F. SISVAR - Sistema de análise de variância. Versão 5.3. Lavras-MG: UFLA, 2010. 
FERREIRA, R. L. F. et al. Avaliação de cultivares de alface com Silifértil ${ }^{R}$. Caatinga, Mossoró, v. 22, n. 2, p. 5-10, abr./jun. 2009.

GALATI, V. C. et al. Aplicação de silício, em hidroponia, na conservação pós-colheita de alface americana 'Lucy Brown' minimamente processada. Ciência Rural, Santa Maria, v. 45, n.11, p. 1932-1938, nov. 2015. https://doi.org/10.1590/0103-8478cr20140334

GERRERO, A. C.; BORGES, L. da S.; FERNANDES, D. M. Efeito da aplicação foliar de silício em rúcula cultivada em dois tipos de solos. Bioscience Journal, Uberlândia, v. 27, n. 4, p. 591-596, jul./ago. 2011.

GOTTARDI, S. et al. Beneficial effects of silicon on hydroponically grown corn salad (Valerianella locusta (L.) Laterr) plants. Plant Physiology and Biochemistry, v. 56, p. 14-23, 2012. https://doi.org/10.1016/i.plaphy.2012.04.002

KIM, S. G. et al. Silicon-induced cell wall fortification of rice leaves: a possible cellular mechanism of enhanced host resistance to blast. Phytopathology, v. 92, p. 1095-1103, 2002. https://doi.org/10.1094/PHYTO.2002.92.10.1095

KORNDÖRFER, G. H.; DATNOFF, L. E. Adubação com silício: uma alternativa no controle de doenças da cana de açúcar e do arroz. Informações Agronômicas, v. 70, p. 1-3, 1995.

MA, J. F.; YAMAJI, N. Functions and transport of silicon in plants. Cellular and molecular life sciences, v. 65, n. 19, p. 3049-3057, 2008. https://doi.org/10.1007/s00018-008-7580-x

MARODIN, J. C. Produtividade, qualidade físico-química e conservação pós-colheita de frutos de tomateiro em função de fontes e doses de silício. 75 f. Dissertação (Mestrado em Agronomia) Universidade Estadual do Centro-Oeste, Paraná, 2011.

RESENDE, G. M. de; YURI, J. E.; SOUZA, R. J. de. Épocas de plantio e doses de silício no rendimento de alface tipo americana. Horticultura Brasileira, Brasília, v. 25, n. 3, p. 455-459, jul./set. 2007. https://doi.org/10.1590/S0102-05362007000300026

SHI, Y.; et al. Silicon decreases chloride transport in rice (Oryza sativa L.) in saline conditions. Journal of Plant Physiology. Stuttgart, v,170, p.847-853, 2013.

YOSHIDA, S. The physiology of silicon in rice. Taipei: Food and Fertilization Technology Center, (FFTC. Technical Bulletin, 25). 1975. 